\title{
In a world in shadows and flames scientists and laypeople need better understanding of how science works
}

\author{
Ulysses Paulino Albuquerque ${ }^{1}$ and Charbel N. El-Hani ${ }^{2}$
}

\begin{abstract}
1 Laboratório de Ecologia e Evolução de Sistemas Socioecológicos, Centro de Biociências, Universidade Federal de Pernambuco and National Institute of Science and Technology on Ethnobiology, Bioprospection and Nature Conservation (INCT EthnoBio), Recife, PE, Brazil.

2 Instituto de Biologia, Universidade Federal da Bahia and National Institute of Science and Technology on Interdisciplinary Studies of Ecology and Evolution (INCT IN-TREE), Salvador, BA, Brazil.

* Corresponding author $\bowtie$. E-mail address: UPA (ulysses.albuquerque@ufpe.br) CNEH (charbel.elhani@gmail.com)
\end{abstract}

Major events, such as pandemics and war, generate great public interest in science, as in the current moment in which we live. We argue, however, that this interest operates through historical pulses and that it does not lead to an increase in scientific literacy in society in general and even among the scientists themselves.

Between 1860 and 1870, Charles Darwin followed with some tension the implications and reception of the Origin of Species (Darwin 2009). He had received applause from many friends, although some did not entirely agree with his theory, while others distilled their hatred and indignation in the press of the time. For instance, on April 101860 Darwin wrote to Charles Lyell about how uncomfortable he felt with Richard Owen's review of his book. This was no minor thing as Owen ranked amongst the most respected paleontologists and comparative anatomists of their days. Darwin narrated how much Owen seemed to distill a particular grudge against him, often spelled out in playful comments and mockery. Darwin's ideas met with much resistance and some reactions were especially harsh and often included cruel attacks on the scientist, not only his ideas. Perhaps one of Darwin's greatest virtues was his persistence and insight in examining different bodies of evidence and proposing a solidly integrative theory. His honesty was also admired, so much so that the North-American botanist Asa Gray wrote on January 231860 to praise his intellectual honesty when declaring that his theory presented difficulties to which he had no answer at the time.

But why come back to that moment in history in our current, strange times? We think there is a point in doing so because that moment holds an important lesson for today: how essential debate is for the production of scientific knowledge, and how personal attacks on scientists are unacceptable, while criticizing their ideas is part of scientific work and, indeed, one of the bases for its quality and objectivity, as shown by Helen Longino's (1990) collective empiricism.

We think that we will not be mistaken in saying that science has suffered important transformations both in its internal relations (between scientists and whole scientific communities) and its external ones (with society). It is rare today, for example, that scientists' activities arise as much interest in the general public as they did in the $19^{\text {th }}$ century. There have been many changes in the institutional framework and mode of organizing academic research in the last 150 years. They include, for instance, transformations in the structure of universities beginning at the end of the $19^{t h}$ century, extending through the $20^{t h}$ century and up to the present. They also include differences in research funding, which became increasingly dominated not only by public funding agencies but also by private corporations, leading to industrialization of scientific knowledge production (Ravetz 1996). There has been a continuous increase in the amount of practicing scientists and scientific knowledge produced, and the relationships between science, technology, and society became deeper and deeper. This was not accompanied, however, by a more qualified and properly critical perspective on scientific work, not only among the lay public, but unfortunately also among some scientists themselves. This has a lot to do with the fact that, with industrialization of scientific knowledge production, scientists became wagelaborers, who also became more often than not alienated from the very nature and conditions of their own 
work.

They maintained, however, their political privilege to speak the truth that might guide decision-making on a number of socioenvironmental affairs (Farrell 2020). But then we came to face increasingly complex and uncertain situations, which need key contributions from science, from global warming to emerging diseases like COVID-19. And, unfortunately, the threatening nature of current situations undermined scientists' authority to speak as representatives of the truth, while their socio-economic status transformed them into instruments of political economy. Since facts continued to afford standing in political discourse, as the authority of scientists waned, the possibility of instrumentalizing facts for political use substantially waxed, immersing us in post-truth politics (Farrell 2020). That facts be inscribed (Latour and Woolgar 1979) is an inevitable consequence of how we need to deeply probe nature to produce scientific evidence: facts are crafted through focused and rigorous attention to the real world. The current circumstances favor, however, that facts be inscribed, and sometimes even invented, for uses that are mostly (sometimes, exclusively) political, rather than epistemic (Farrell 2020).

We can see such instrumentalization of facts for political purposes in Donald Trump's claim that hydroxychloroquine (HCQ) would allegedly be "one of the biggest game-changers in the history of medicine". The basis for this claim was an open-label nonrandomized controlled clinical trial (Gautret et al. 2020), which has been harshly criticized for its limitations and methodological flaws (e.g., Kim et al. 2020). The exaggerated appreciation of preliminary, limited results, which have been amplified in professional and social media due to their political instrumentalization led to drug shortages for patients who need it for approved treatments, self-medication, even intoxication, and death. Other political figures, such as Jair Bolsonaro, current Brazilian president, joined Trump in the enthusiasm, while suspicion of hidden political agendas and economic interests has been raised. The implications have been very serious, with a decrease in the adherence of people to public health measures that are the only well-established means to control the pandemic, such as physical distancing and isolation (e.g., Wilder-Smith and Freedman 2020).

Clinical trials of other treatments were affected be- cause patients were so convinced of HCQ's alleged benefits that did not accept being treated otherwise (Ledford 2020). And then the promises failed. Currently, most countries have reconsidered the endorsement of HCQ for COVID-19 treatment, with some exceptions, like Brazil. Moreover, the HCQ arm has been interrupted in several large-scale clinical trials. On June $5^{t h}$, the UK's RECOVERY RCT announced that recruitment into the HCQ arm had been stopped due to the lack of benefit on 28-day mortality (primary endpoint), length of hospitalization and other outcomes $^{1}$. This was followed by the announcement by WHO on June $17^{\text {th }}$ that the HCQ arm of the SOLIDARITY Trial was being interrupted, based on evidence obtained by the SOLIDARITY RCT itself and the UK's RECOVERY trial, and on a Cochrane review of evidence on HCQ showing that this drug does not result in reduced mortality of hospitalized COVID-19 patients, when compared with standard of care $^{2}$. In France, the Agence Nationale de Sécurité du Médicament et des Produits de Santé (ANSM) communicated on June $18^{\text {th }}$ the suspension of the HCQ arm of the DISCOVERY RCT (as well as all HCQ studies in progress in France) due to lack of efficacy ${ }^{3}$. On June $20^{t h}$ the U.S. National Institutes of Health (NIH) announced the interruption of the ORCHID clinical trial to evaluate the safety and effectiveness of HCQ for the treatment of adults hospitalized with COVID-19 as the evidence gathered showed that the treatment does no produce harm, but provides no benefit ${ }^{4}$. The current post-truth political period is quite far from what many might expect from the increase in knowledge along the last 150 years. But this expectation may not be well-founded in the end. First, a balanced increase in knowledge in all relevant fields to think the current circumstances does not follow from increase in knowledge in general. The industrialization of scientific knowledge production seems to have entailed much more knowledge on how to intervene on nature and ourselves than on how to properly appraise the risks and consequences of our actions and how to be prudent enough in such interventions.

Second, history seems to teach us that we operate based on "pulses" or "major events" that at a given moment generate significant interest in science and its discoveries. That is not necessarily accompanied, however, by greater scientific literacy of the general public, and, unfortunately, properly critical perspec-

\footnotetext{
${ }^{1}$ No clinical benefit from use of hydroxychloroquine in hospitalized patients with COVID-19, Available at: https://www.recoverytrial.net/news/statement-from-the-chief-investigators-of-the-randomised-evaluation-of-covid-19-therapyrecovery-trial-on-hydroxychloroquine-5-june-2020-no-clinical-benefit-from-use-of-hydroxychloroquine-in-hospitalised-patients-withcovid-19, Accessed December $12^{t h}$ 2020. See also The RECOVERY Collaborative Group. New England Journal of Medicine 383, 2030-2040.

2 https://www.who.int/news/item/04-07-2020-who-discontinues-hydroxychloroquine-and-lopinavir-ritonavir-treatment-armsfor-covid-19, Accessed December $12^{\text {th }} 2020$.

${ }^{3}$ https://www.chu-lyon.fr/fr/covid-19-essai-discovery, Accessed December $12^{\text {th }} 2020$.

${ }^{4}$ https://www.nih.gov/news-events/news-releases/nih-halts-clinical-trial-hydroxychloroquine, Accessed December $12^{t h} 2020$.
} 
tive on scientific work and its relations to technology and society on the part of scientists themselves. Wars are examples of driving forces for high pulses of interest in science. Rossiter (1985) analyzes how North-American science, after the Second World War, received great incentives, experiencing steady growth. This is a trend that seems to accompany these moments in human history, as science is expected to find answers to the new challenges created by major events. However, at the times of post-truth politics, science may be used not necessarily to find answers only, but also to manipulate political discourse.

One might expect that these calamitous events generate not only innumerable challenges, but also opportunities for greater public understanding of science, as well as increasing public incentives for research. But there is no necessary entailment between these events and consequences. In 1989, Isaac Asimov wrote to the Los Angeles Times, narrating turbulent times when several studies indicated that North-American students were illiterate in science and mathematics:

(...) there are millions of people in the United States who still firmly believe that every word of the Bible is inspired and absolutely, literally true; that the sun is moving and Joshua did command it to stand still, and it did stop moving temporarily.

We can join Asimov in his regret, as there are people who, after so many years of quality science, pandemics, and wars, still defend, sometimes fanatically, that the planet is flat, and vaccines are harmful to our health! We are experiencing an unimaginable even greater movement in this direction, which has several causes, ranging from science education too focused on conclusions of scientific work, rather than understanding how science works, to the appropriation of facts as mere instruments for power struggles, with shrinking interest in their truth value. We face a devastating pandemic associated, in many countries, with coordinated instrumentalization of scientific facts to weaken all efforts to control the disease, a phenomenon that also reveals scientific illiteracy among the public, decision-makers, and even, professionals with higher education. This does not exclude scientists, which may be illiterate on sciencetechnology-society (STS) relationships and the risks that scientific studies are instrumentalized for political use. Such illiteracy on STS relationships goes a long way towards explaining how physicians fighting on the front lines against COVID-19 may recommend treatment with azithromycin, ivermectin, and chloroquine even without the support of scientific evidence, merely grounding their recommendation on the weak claim that "people have improved".
This scenario seems to teach that history repeats itself in vicious cycles that need to be broken. If Darwin shared our current times, he would see scientists being threatened simply because they did their work judiciously; people denying science based on personal beliefs and political interests, or worse instrumentalizing science to their own political goals with no attention to truth; suffering professionals going against the grain of science, simply because they do not seem to understand the scientific practices or STS relationships; and thousands of frightened people who do not understand science, because we still have not figured out the best way to teach them about how it works and how it relates to society, losing precious educational time packing up their minds with encyclopedic curricula. Both scientists and laypeople should understand how crucial critical and informed debate is for the objectivity of scientific knowledge, but that the debate should be about ideas, not scientists themselves.

\section{REFERENCES}

Asimov I (1989) Combatting U.S. Scientific Illiteracy. Los Angeles Times, March 31, 1989. https://www.latimes.com/archives/la-xpm1989-03-31-vw-543-story.html Accessed 18 May 2020.

Darwin C (2009) A evolução: cartas seletas de Charles Darwin 1860-1870. São Paulo: Editora Unesp.

Farrell KN (2020) Untrol: Post-Truth and the new normal of post-normal science. Social Epistemology. doi: 10.1080/02691728.2019.1706117 Accessed 15 May 2020.

Gautret P, Lagier J C, Parola P, Hoang VT, Meddeb L, Mailhe M, Doudier B, Courjon J, Giordanengo V, Vieira VE, Dupont HT, Honoré S, Colson P, Chabrière E, La Scola B, Rolain JM, Brouqui P, Raoult D (2020) Hydroxychloroquine and azithromycin as a treatment of COVID-19: results of an open-label non-randomized clinical trial. Journal of Antimicrobial Agents. Journal PreProof. doi: 10.1016/j.ijantimicag.2020.105949 Accessed 28 April 2020.

Kim AHJ, Sparks JA, Liew JW, Putman MS, Berenbaum F, Duarte-García A, Graef ER, Korsten P, Sattui SE, Sirotich E, Ugarte-Gil MF, Webb K, Grainger $\mathrm{R}$, for the COVID-19 Global Rheumatology Alliance (2020) A rush to judgment? Rapid reporting and dissemination of results and its consequences regarding the use of hydroxychloroquine for COVID-19. Annals of Internal Medicine, In press. doi: 10.7326/M20-1223 Accessed 20 May 
2020.

Latour B, Woolgar S (1979) Laboratory Life: The Social Construction of Scientific Facts. London: Sage.

Ledford H (2020) Chloroquine hype is derailing the search for coronavirus treatments. Nature 580: 573 .

Longino H (1990) Science as Social Knowledge: Values and Objectivity in Scientific Inquiry. Princeton, NJ: Princeton University Press.
Ravetz JR (1996) Scientific Knowledge and Its Social Problems. New Brunswick, NJ: Transaction.

Rossiter MW (1985) Science and Public Policy since World War II. Osiris 1: 273-294.

Wilder-Smith A, Freedman DO (2020) Isolation, quarantine, social distancing and community containment: pivotal role for old-style public health measures in the novel coronavirus (2019-nCoV) outbreak. Journal of Travel Medicine 27(2): taaa020. 